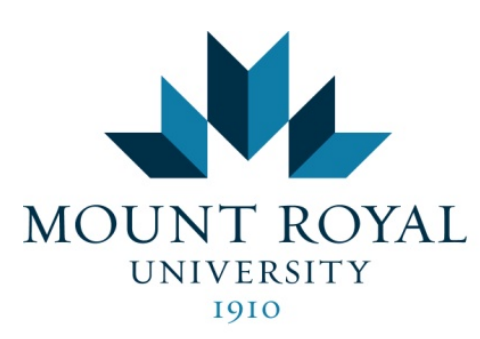

Mount Royal Undergraduate Education Review
Department of Education and Schooling

Volume 1(1)

Spring 2014

\title{
Equality in education: The digital divide
}

Melanie Morrow, Mount Royal University

\begin{abstract}
Equality in Alberta education in terms of access to technology, better known as the digital divide, is analyzed and explored in this research study. The question as to whether each child should have equal opportunity to the same quality education is an easy question to answer. However, there are discrepancies and inequalities that remain within our system, and as a result, quality education for learners is being affected. Data for this study was collected through a Google Forms online survey and was sent out via social media. Various interviews were also conducted. The findings suggest that parents, post-secondary students, and other members of society are concerned about equality in education as well as the use of technology in the elementary classroom.
\end{abstract}




\section{Introduction}

Reflecting upon my own experiences in terms of inequality has led me to be deeply concerned about the inequality that exists in our Alberta education system. Growing up in a single parent family and being faced with adversity, particularly in my school age years, has led me to be an advocate for children who are less fortunate. I have developed a keen interest in how our education system tackles inequality and I believe that providing equal learning opportunities for every child we encounter as teachers should be a moral responsibility as well as a priority. Equal opportunity should not be negotiated between different school communities, especially within the public school board. A child should not suffer in any way shape or form in terms of the quality of their education because of individual differences such as, social status, lack of financial support, or family dynamics. Growing up in a community and going to a school where I financially did not fit in, I was able to experience how it felt to be surrounded by people who had opportunities that I had only dreamed of. Since my childhood, the use of digital technologies has exploded beyond measure and I could imagine how I would have felt if I were growing up as I did, now.

My interest in equality education is not a new interest and it is constantly evolving with new questions. Recently, a question has arisen concerning digital technologies and whether or not they are equally accessible to all students in Alberta. This question arose while in my last school placement. I was fortunate during my field experience to be placed in a elementary school, which evidently had no issues in terms of funding for technology. Each class came equipped with a SMART Board, an iPad for a centre activity, and each teacher had their own personal Apple laptop. There was also a cart with 40 iPads that were available to teachers to reserve for class activities. The library was equipped with 20 brand new Apple computers. They 
even had a, "green screen” which allowed learners and teachers to make interactive videos. There was clearly no lack of technology integration here, and these learners were extremely fortunate to have such modern equipment. I couldn't help but notice that this was the first school I had seen with such diverse and accessible means for technology. I began wondering why other public schools I have had the chance to visit, including Lethbridge elementary schools, did not have the same opportunities to use technology as a learning tool?

The discrepancies between the accessibility of technology at different schools within our province is an important issue and concern for me. If the implementation of technology in the classroom benefits students and their learning in a measurable way, why aren't all schools provided with the same opportunities? If in fact technology enhances student success, influences self-motivation, and fosters student engagement shouldn’t each school within the public system receive the same amount of funding? I feel as though creating school environments, which are unequal in instructional material is unacceptable and contradicting to the new push for inclusive education. It is important to note that not every school should be expected to function in the same manner, as education works best when it is not formulaic. Individual differences as well as community differences are important in teaching children other valuable things about life. However, elementary schools should all have equal opportunity to utilize special programs and experience technology in an educational way.

\section{Background and Literature Review}

The background information regarding equality in terms of digital technology in elementary schools stems from various sources. One area of information comes from Alberta Government documents containing information regarding government funding, community funding, and grants. These are essentially all of the economic factors that affect the quality and 
equality of our education system. It also stems from the increase in the implementation of technology as an instructional tool. Previous research done on this topic focuses on the integration of technology in the classroom. It uses mostly a critical position towards technology and analyzes its benefits as well as its drawbacks, admits there are gaps, and attempts to suggest possible solutions.

\section{Related Literature}

During my research regarding previously published work on the topic I came across various articles commenting on the implementation and utilization of digital technology in a classroom setting. A major theme presented in the literature is the fact that technology can only be beneficial when it is being used correctly. In Friedman's (1999) article, "What students should know about technology: The case of scientific visualization,” he touches upon this allegation and suggests that technology in a classroom can only be evaluated in the context that it is used. It is important to evaluate the technology in whether or not it is successful in teaching or representing what it is intended to. The way in which Friedman (1999) describes technology to be a representational device was also an interesting perspective. I agree with this claim as computer programs can be used to create all sorts of representations to enhance student learning. For instance, a graph is made simply with a computer program. Within the event of a student making a representational graph on the computer the student is learning computer literacy skills, which may benefit there her or him in the future, as well as strengthening their ability to sort through and organize data. With this in mind it may be correct to assume that a student with access to such programs may have an advantage when it comes to science or math.

Similarly, Bernard, Abrami and Lou (2004) describe in their article, "How does distance education compare with classroom instruction? A meta-analysis of the empirical literature” the 
different affordances of technology. The article states that technology can be used as a collaborative tool, which is absolutely true. An interesting claim caught my attention in the introduction of this piece that introduces the idea that the use of technology and its benefits rest solely upon how the student uses the device. "It's what the learner does with a medium that counts” (Bernard, Abrami \& Lou, 2004, p.381). This claim struck my attention because it begs the question, if benefits rest solely upon the individuals use and understanding of a device, what happens to the students who don’t have access to particular devices? Should technological devices only serve benefits for those children who are fortunate to have access to them? Technology should be distributed and implemented equally in each and every school, if it is to be implemented at all. The unequal distribution of instructional tools only creates learning gaps in our education system.

Another interesting theme projected through previously done research were the drawbacks of technology. An article by Hew and Brush (2007) entitled "Integrating technology into k-12 teaching and learning: Current knowledge gaps and recommendations for future research" recognizes that the use of technology as an instructional tool will face barriers. This is important to acknowledge. One barrier that the article mentions, which is directly connected to my question is how to overcome the, "scarcity of resources"(Hew \& Brush, 2007, p.238). The article not only states that the scarcity of resources in schools is a problem, it also offers possible strategies for schools to fix the problems. Quality of education needs to be made a priority. Schooling isn't about managing students; it's about empowering them and providing them with the means for a higher education. 


\section{Research Context}

My research was conducted in two Alberta cities, Lethbridge and Calgary. Lethbridge was included in my research as the University of Lethbridge has a fairly reputable Faculty of Education and I was interested in comparing the integration and accessibility of technology in the two opposing Alberta locations. Data was collected using social media, Google Forms surveys, previously published articles, and personal interviews. The research included reflections of my own experiences with technology as well as observations at various elementary schools in Lethbridge and Calgary.

The participants in this research included 20 individuals who were interested in completing my Google Forms survey, which was sent out via social media. Individuals were not specifically asked to complete the survey in order to avoid bias. Participants included education students from Mount Royal University, education students from the University of Lethbridge, peers from various academic backgrounds, parents, and co-workers. Participants were assured that their information and participation in the research would remain anonymous. Gaining permission from parents or guardians was not necessary as discussions with children were not directly a part of the research. Observations of children utilizing technology and their experiences however, were used in the research.

Two interview participants volunteered their information and experiences with the assurance that their personal information would be kept confidential. One interviewee was asked particular questions about his experiences and observations regarding technology in terms of equal access throughout various Lethbridge elementary schools. Another interviewee was asked questions about her experience as a parent with a child who did not have equal access to technology due to social circumstances. 


\section{Methods of Investigation}

In general, my research design was primarily inquiry based. Participants were asked various questions concerning technology in general, as well as its implications in the classroom. I explored and utilized a variety of formats to collect data such as;

- social media

- surveys

- field notes

- teaching journals

- interviews

- existing literature

- mentor teachers

- peers from education

- $\quad$ peers from various academic backgrounds

- parents

My interviews were conducted in person and I took point form notes during the sessions. Social media and survey results were organized using Google Spreadsheets. Graphs as well as analytical work were done to understand the implications of my research findings.

\section{Findings}

It became clear from the analysis of my research data that individuals in Alberta believe technology is a resourceful learning and teaching tool. The findings also indicate that there is agreement that children deserve equal opportunity to succeed regardless of their circumstances.

My first survey question asked participants if they thought the use of digital technologies in elementary education was increasing learning (Figure 1). 


\section{Do you think technology is increasing learning?}

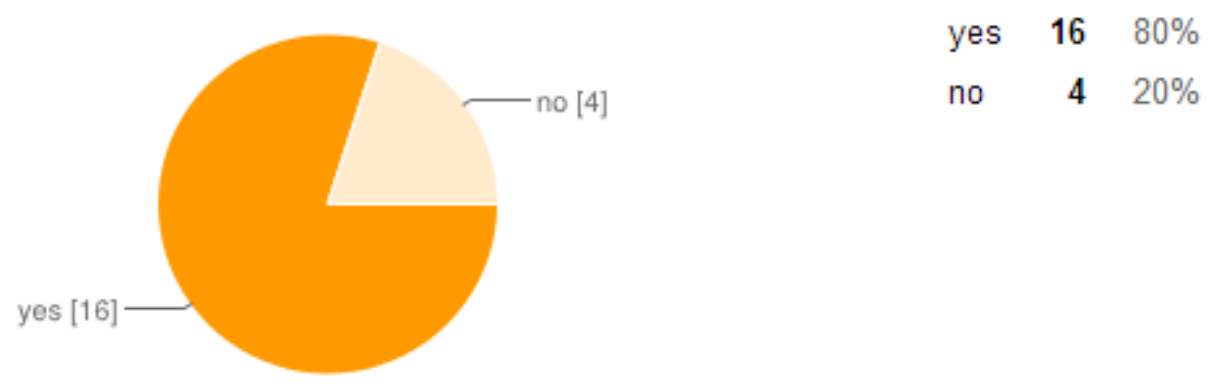

Figure 1. Technologies impact on learning

The graph in Figure 1 indicates that there is accordance in the fact that technology may be successful in increasing student learning, which ultimately is a primary goal of a teacher.

My next question asked participants if they thought a lack of access to technology impacted student learning (Figure 2).

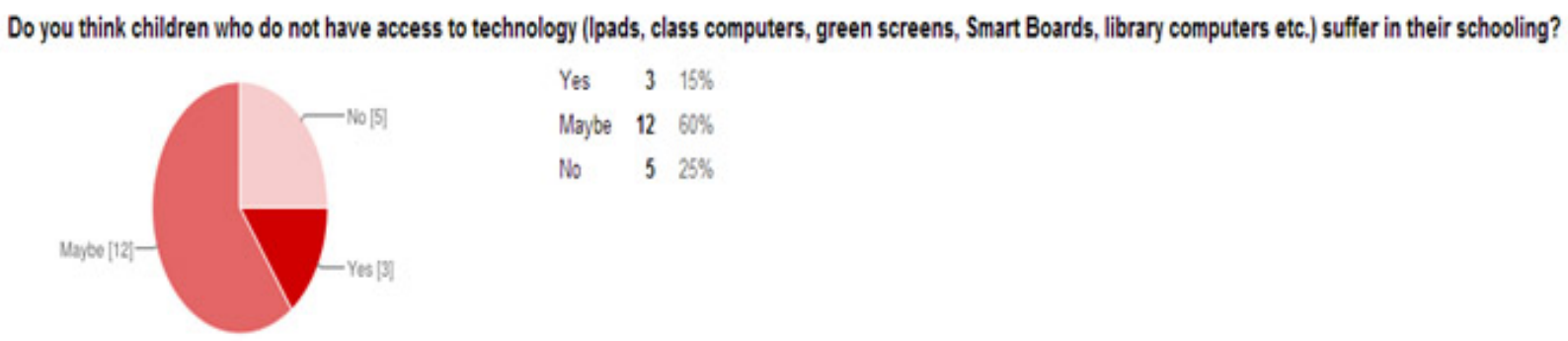

Figure 2. Does lack of access impact students learning?

There was no solid answer given for this question as it seems participants did not seem to agree in this matter. I personally believe that if you were to take two students, one with computer literacy and one without, and compared the two (which you really shouldn't do as a teacher) you would undoubtedly find differences in their engagement and perhaps even in the quality of their work. The options for presentation with technology are vast and engaging whereas regular written assignments become tedious. Technology also facilitates learning for those students who 
find traditional assignment work and presentations less than exciting.

The next question explored whether the survey participants thought that every child in Alberta deserved equal access to digital technologies in elementary education.

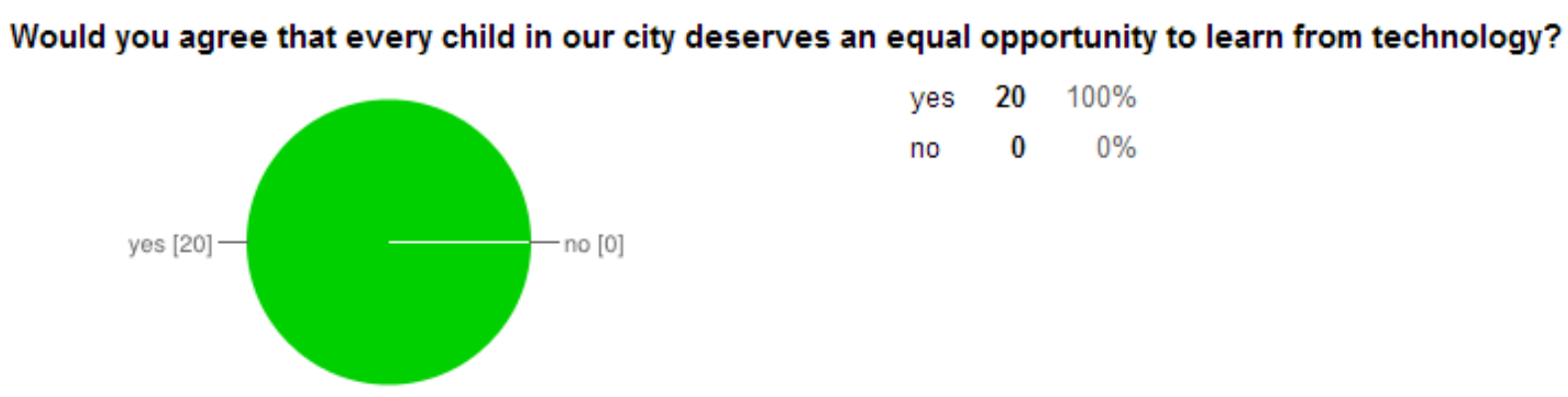

Figure 3. Equal opportunity to learn from technology

This graph and the results are quite self explanatory. Clearly there is an undeniable acknowledgment of the fact that every child should have equal access to learning tools. Unfortunately, regardless of this, equality in terms of technology at elementary schools within the province of Alberta is not a reality.

I was then curious to know if participants thought that the benefits of technology as a learning tool where just hype (all talk, no action) or actually real (Figure 4).

Are the benefits of technology as a learning tool all "talk"?

$\begin{array}{lrr}\text { yes } & 0 & 0 \% \\ \text { no } & 20 & 100 \%\end{array}$
no [20]- $\quad$-yes [0]

Figure 4. Are technology benefits real?

Once again, participants are in accordance that the implementation of technology is 
beneficial.

Figure 5 demonstrates that participants unanimously agreed that financial circumstances should not affect the quality of a child's education in Alberta.

\section{Should the financial circumstances of a child effect the quality of their education?}

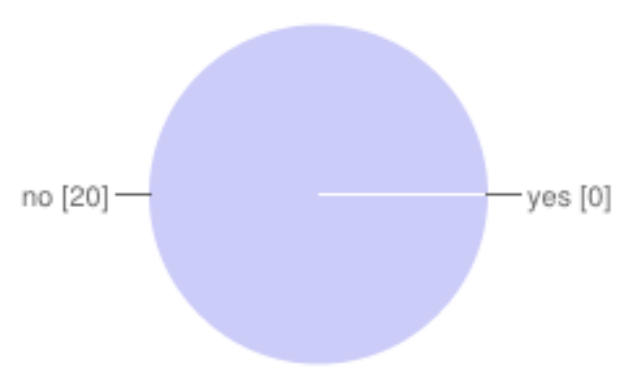

$\begin{array}{lrr}\text { yes } & 0 & 0 \% \\ \text { no } & 20 & 100 \%\end{array}$

Figure 5. Financial circumstances

The final two figures illustrate that the majority of the survey participants use a laptop in their education studies at that they believe their learning would be negatively impacted if they did not have access to this digital device (Figures 6 and 7).
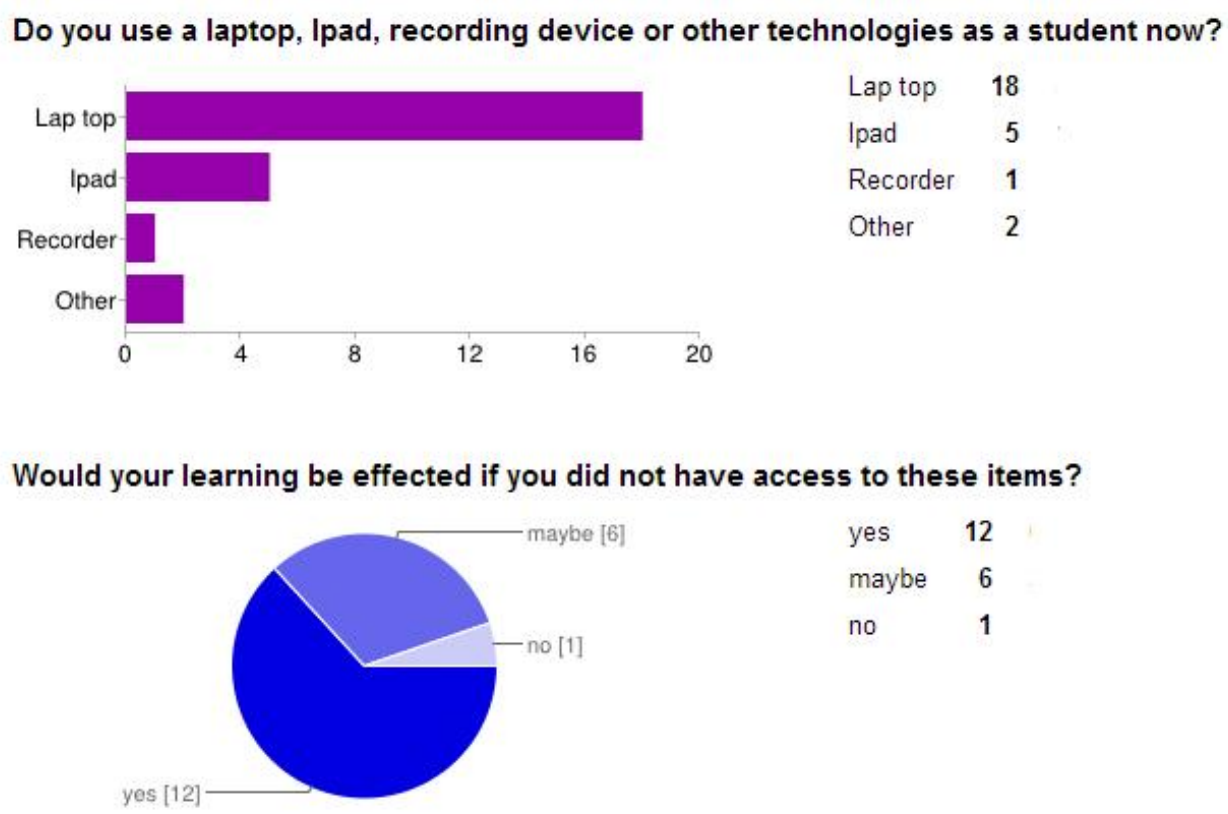

Figure 6 and 7. Survey participants' use of technology 


\section{Conclusions and Recommendations}

Considering my research, as well as previous related studies, it becomes clear that technology integration has created quite the buzz amongst education advocates. Considering my own motivations in becoming a professional teacher, I know how important it is to be engaged. I agree without a doubt that technology, if used correctly, is a tremendous tool to facilitate and encourage your students in an engaging manner. The ideas and opportunities for students to imagine, create, and learn are endless when you incorporate traditional technologies with new digital technologies. It can no longer be ignored that the accessibility to these learning tools varies from school to school and city to city within our province. This suggests that the quality of education does not necessarily hold the same priority in all cases. Albertan citizens and our governments are morally responsible for the quality of education we provide our future generations. The tools and knowledge that we invest in education will ensure the vitality of our cities and our futures.

The digital divide certainly is not just about technology. It’s about accessibility, funding, integration, inquiry, social status, family dynamics, and socio economic status. I think that equality and reasonable accessibility for technology in schools is and should be important to everyone involved in the school community. Teachers, parents, volunteers, principals, and board members should all be concerned about the quality of every school's instructional tools, in particular technological tools. 


\section{References}

Bernard, R., Abrami, P. C., \& Lou, Y. (2004). How does distance education compare with classroom instruction? A meta-analysis of the empirical literature. Review of Educational Research , 74(3), 379-439.

Freidman, J. S., \& Disessa, A. A. (1999). What students should know about technology: The case of scientific visualization. Journal of Science Education and Technology , 8(3), 175195.

Hew, K., \& Brush, T. (2007). Integrating technology into k-12 teaching and learning: Current knowledge gaps and recommendations for future research. Educational Technology Research and Development , 55(3), 223-252. 